\title{
ACCESO Y USO DE INTERNET EN COOPERATIVISTAS AGROPECUARIOS CUBANOS
}

\begin{abstract}
Resumen: El Estado cubano viene aprobando normativas para consolidar y diversificar el cooperativismo agropecuario y para lograr el Objetivo de Hambre Cero para 2030. Siendo el primero estudio sobre el uso y acceso de internet de los cooperativistas agropecuarios cubanos, los resultados de los cuestionarios aplicados apuntan la participación marcadamente masculina; desigualdades de género en los entornos rurales; insuficiente participación de los jóvenes; marcado interés demostrado por cooperativistas de la zona oriental del país; frecuencia del acceso regular, básicamente diaria, doméstica, fundamentalmente nocturna y a partir de los datos móviles; socialización en el uso de las redes para compartir y mantener el contacto con amigos y otros usuarios. Los mismos resultados sirven de antecedente para implementar una multiplataforma digital que articule los contenidos de varios escenarios comunicativos (televisión, radio, redes sociales, moodle, etc.) sobre buenas prácticas endógenas que eleve la cultura cooperativa y sintonice con otros públicos y promueva una percepción social acorde a la cultura digital y las necesidades de desarrollo sostenible en el país.
\end{abstract}

Palabras clave: uso y acceso de internet; cooperativismo agropecuario; Cuba.

\author{
Ania Rosa Hernández Quintana \\ Doctora en Ciencias de la Información. \\ Profesora Titular de la Facultad de \\ Comunicación de la Universidad \\ de La Habana \\ aniahdez@fcom.uh.cu
}

Manuel Alejandro Romero Quesada Mestre en Bibliotecología y Ciencias de la Información. Profesor de la Facultad de Comunicación de la Universidad

de La Habana

manuel.romero@fcom.uh.cu

Disamis Arcia Muñoz

Licenciada en Comunicación

Profesores de la Facultad de

Comunicación de la Universidad

de La Habana

disamis@fcom.uh.cu

\section{ACCESS AND USE OF THE INTERNET IN CUBAN FARMING COOPERATIVISTS}

\begin{abstract}
The Cuban State has been approving regulations consolidating and diversifying agricultural cooperatives to achieve the Zero Hunger Goal for 2030. Being the first study about the use and access of the internet by Cuban agricultural cooperatives, the results of the applied questionnaires point to: a markedly male participation; gender inequalities in rural settings; insufficient participation of young people; marked interest by cooperative members in the eastern part of the country; frequency of regular access, basically daily, domestic, mainly at night and based on mobile data; use of networks to share and maintain contact with friends and other users. The some results serve as a precedent to implement a digital multiplatform that articulates the contents of various communication scenarios (television, radio, social networks, moodle, etc.) on endogenous good practices that elevate the cooperative culture and tune in with other audiences and promote a social perception in accordance with the digital culture and the needs of sustainable development in the country.
\end{abstract}

Keywords: internet access and use; agricultural cooperativism; Cuba.

\section{INTRODUCCIÓN}

Con la aprobación en 1982 de la primera norma ${ }^{1}$ con carácter específico que regula todo lo concerniente a las Cooperativas de Producción Agropecuaria (CPA) y con las

\footnotetext{
${ }^{1}$ Ley No. 36 de 1982, Ley de Cooperativas Agropecuarias. En: Gaceta Oficial de la República de Cuba, Edición Ordinaria, No. 63, La Habana, 4 de julio de 1982.
} 
modificaciones $^{2}$ posteriores, se confirma el interés del Estado cubano por desarrollar la propiedad colectiva, un modelo priorizado en la actualidad para alcanzar la seguridad y soberanía alimentaria. ${ }^{3}$

Consolidar y diversificar el cooperativismo agropecuario es fundamental para lograr el Objetivo de Hambre Cero para 2030, pero para ello se requiere una transformación radical del sistema agroalimentario, con soluciones más productivas, eficientes, sostenibles, inclusivas, transparentes y resilientes (FAO, 2017 p. 140).

Una parte de esos cambios se relacionan con mayores facilidades para la adquisición de dispositivos inteligentes, el aumento del acceso a internet y el fortalecimiento de las competencias y habilidades mediáticas e informacionales por parte de las socias y socios de las cooperativas agropecuarias. Con esas capacidades formadas, estarán en mejores condiciones para actuar con autonomía y responsabilidad, promover la inclusión en la gestión cooperativa y ejercer transparentemente las facultades administrativas o de control.

Los escenarios productivos en las áreas de la agricultura cañera y no cañera y la ganadería vacuna están urgidos de renovar en unos casos y de preservar en otros, sus prácticas culturales desde la creatividad y la inteligencia individual y colectiva, con las contribuciones de todas las generaciones y con perspectiva de género, a través de un acercamiento crítico, creativo e innovador a las fuentes y recursos de conocimientos que se gestionan en las plataformas digitales. El uso de internet y las redes sociales digitales se relaciona con la sustentabilidad de las producciones agropecuarias en tanto facilitan el conocimiento de los contextos, valores y principios del cooperativismo y contribuyen al bienestar de las y los cooperativistas y sus familiares.

En Cuba, con el 85,6\% de cobertura de la población con telefonía móvil (ONEI, 2021, p. 7), es momento de plantear políticas y estrategias que doten de mayores oportunidades a las y los cooperativistas agropecuarios para participar de un sistema agroalimentario de base digital (Trendov et al., 2019), pero primero habrá que crear y/o fortalecer sus posibilidades y capacidades para articular de forma autónoma y responsable con las complejidades de la brecha digital, del acceso pleno a la información digital y la convergencia de los medios.

\footnotetext{
${ }^{2}$ Ley No.95 de 2002, Ley de Cooperativas de Producción Agropecuaria y de Créditos y Servicios. En: Gaceta Oficial de la República de Cuba, Edición Ordinaria, No.72, La Habana, de 29 de noviembre de 2002.

${ }^{3}$ El papel estratégico de las cooperativas aparece en la Actualización de los Lineamientos de la Política Económica y Social del Partido y la Revolución para el período 2016-2021 y se explicita en el Plan Nacional de Desarrollo Económico y Social hasta el 2030: Visión de la Nación, Ejes y Sectores Estratégicos.
} 
De momento, el sector cooperativo agropecuario cubano continúa enfrentando un proceso de apropiación de las TIC (Sandoval, 2019) más que un proceso formal de Alfabetización Mediática e Informacional (AMI). Mientras que la apropiación es un acto de "conquista" del artefacto y de adaptación a sus usos y efectos, tanto como de no uso, la AMI se ventila como un programa interseccional a lo largo de la vida para empoderar y ejercer derechos universales.

La AMI es un concepto compuesto que articula la alfabetización tecnológica o propiamente digital, la informacional y la mediática en el orden de la creación y fortalecimiento de capacidades para acceder, recuperar, usar, crear, así como compartir información y contenidos mediáticos en forma crítica, ética, y efectiva, en todos los formatos y desde múltiples herramientas, todo lo cual se asienta, entre otros, en el derecho de acceso universal a la información (UNESCO, 20013).

La crisis global producida por la COVID-19 ha evidenciado que, gracias a la penetración de la conectividad digital, ha sido posible continuar realizando muchas funciones de alta sensibilidad y que las formas de interacción social y de acceso a la información a través de plataformas digitales está siendo una de las marcas de este período. En el contexto pandémico, como se evidencia cada día, aumenta la frecuencia de uso de los contenidos digitales, no solo para mantener el contacto social, sino con fines comerciales, educativos o formativos, de ocio y placer. Mientras, en una dimensión más crítica, con la pandemia también se refuerzan las diferencias entre el norte y el sur global en cuanto a la brecha digital, entendida en términos de conectividad, acceso y uso de internet, a la vez que se profundizan los desequilibrios en la cadena de valor de los datos (UNCTAD, 2021).

Si la pandemia planteó toda suerte de desafíos a los cooperativistas agropecuarios cubanos, incluyendo las limitaciones de acceso a las TIC, la pospandemia puede ser un escenario para intentar establecer o reforzar una relación más próxima e igualitaria con los dispositivos, las plataformas y las herramientas digitales, para usar y crear autónoma y responsablemente contenidos hipermedia que impulsen los sistemas alimentarios soberanos y sostenibles en Cuba.

Las oportunidades para el acceso pleno a la información redundan en la participación activa en el proyecto cooperativista agropecuario y consolidan el presupuesto constitucional de construir "una sociedad de la información y el conocimiento centrada en la persona, integradora y orientada al desarrollo sostenible, en la que todos puedan crear, consultar, utilizar y compartir 
la información y el conocimiento en la mejora de su calidad de vida" (Constitución de la República de Cuba, 16m, 2019).

El presente estudio es el primero en aproximarse al uso de internet por parte de las y los cooperativistas agropecuarios cubanos. Los perfiles que se alcanzan, además de ser útiles para conocer el estado de la brecha digital, sirven de antecedente para implementar una multiplataforma digital que articule los contenidos de varios escenarios comunicativos (televisión, radio, redes sociales, moodle, etc.) sobre buenas prácticas endógenas que eleve la cultura cooperativa de socias y socios, pero que también sintonice con otros públicos y promueva una percepción social acorde a la cultura digital y las necesidades de desarrollo sostenible en el país.

A su vez, la multiplataforma digital a la que se aspira es apenas la excusa para fundar un proyecto mayor que alcance la transformación digital de la agricultura cubana, para lo cual no solo se requiere el aumento del uso de la telefonía móvil y de internet entre las y los cooperativistas agropecuarios, sino que es necesario generar y profundizar las capacidades digitales en la población rural y promover la cultura agroempresarial digital basada en la innovación. Para este empeño será crucial el acompañamiento permanente de las generaciones más jóvenes, así como de facilitadores y programas de formación especialmente diseñados para ser implementados en los diversos contextos rurales.

En todo caso, esos planes solo pueden comenzar desde el descubrimiento de las características del uso de las tecnologías digitales y el acceso a internet, que primero sucede para la comunicación interpersonal pero que luego, de forma más sofisticada, sirve para encontrar soluciones informadas a los problemas de la agricultura cubana en general y de las cooperativas agropecuarias en particular, incrementar los rendimientos, reducir las repercusiones ambientales y mejorar los medios de vida.

\section{COOPERATIVAS AGROPECUARIAS EN CUBA}

Durante décadas, el ámbito casi exclusivo de existencia de cooperativas en Cuba lo fue el entorno de la producción agropecuaria. Su origen puede enmarcarse a partir de la firma de las dos leyes fundamentales de Reforma Agraria (1959 y 1963) que produjeron transformaciones radicales en las estructuras productivas y sociales del "campo cubano", que 
dieron lugar al surgimiento de nuevos sujetos agropecuarios, y expresaron una tendencia a la socialización de las relaciones de producción agraria (Valdés Paz, 2010, p. 15).

Como parte de ese proceso de cambios entre los que se encontraban la nacionalización de latifundios y la entrega de tierras a las familias campesinas, surgieron también experiencias tempranas de cooperación entre las que puede enumerarse la creación en 1960 de las Cooperativas Cañeras, como una modalidad de gestión socializada de las granjas que habían pasado a propiedad del Estado cubano. Pocos meses después comenzaron a organizarse las Cooperativas de Créditos y Servicios (CCS), principalmente entre los productores tabacaleros de Pinar del Río y la antigua provincia de Las Villas que disponían de medios de producción, nacionalizados, de uso común.

De acuerdo con las publicaciones estadísticas de la época, ${ }^{4}$ en el año 1963 existían ya 587 de estas cooperativas. Otras experiencias de cooperación incluyeron la existencia de las llamadas Sociedades Agropecuarias, una forma de producción promovida en varias provincias del país, en particular entre los productores de caña y ganado, basada en la propiedad común sobre la tierra y demás medios de producción. Solo llegaron a crearse unas 70 de ellas.

Sin la existencia, en esos primeros años, de una política nacional de cooperativización, lo cierto es que muchas de estas experiencias solo llegaron a involucrar a un pequeño porcentaje del campesinado. No sería hasta unos años después, en 1975, que surgirían las Cooperativas de Producción Agropecuaria (CPA) como otra modalidad dentro del sector agropecuario. A diferencia de las ya existentes CCS, las CPA surgen como resultado del aporte de los campesinos de las tierras de su propiedad, bajos los principios de la propiedad colectiva de todos los medios de producción; la ausencia de parcelas familiares y la producción colectiva del autoconsumo; la equiparación tecnológica con las empresas estatales; la responsabilidad social con el entorno en que se encontraban; entre otros principios. Estas primeras CPA contaron con un fuerte apoyo estatal, concretado en numerosos casos en la cesión de áreas, la dotación de medios de producción y el otorgamiento de créditos de inversión. A finales de 1979 se habían creado más de 800 de estas entidades, y en la década siguiente ese ritmo de crecimiento se triplicó.

Aunque durante los años que siguieron resalta la creación de las Uniones Municipales de Cooperativas (UMCA), que debían funcionar como una especie de cooperativas de segundo grado, orientada a dar servicios de intermediario con las empresas estatales a las CCS y las

\footnotetext{
${ }^{4}$ Juan Valdés Paz cita en su estudio el folleto Las empresas del INRA:1962, sin otros datos.
} 
CPA, estas tuvieron una vida efímera, y en un contexto donde primaba la mentalidad de la superioridad de la empresa estatal por encima de la gestión cooperativa, las potencialidades y capacidades reales fueron desaprovechadas en su calidad no solo de entidades de producción material de la vida, sino también como espacios de socialización y de creación de una cultura en función del bien colectivo.

Tan solo en términos de participación en la producción agrícola, varios estudios dan cuenta de cómo las cooperativas eran concebidas como "hermanas menores" dentro del sector agropecuario, donde la administración de casi el $75 \%$ del fondo de tierras y otros medios de producción se encontraba bajo las grandes empresas estatales.

A inicios de los años noventa del siglo XX Cuba comenzó a experimentar una seria crisis económica que dio inicio al llamado Período Especial. Como parte de las estrategias de recuperación implementadas en el sector agropecuario a partir de 1993, se puso en práctica un grupo de transformaciones que apuntaron no solo a la reestructuración de la tenencia de la tierra, sino que también condujeron a una reorganización de los productores y a la diversificación de las formas de organización productiva (Valdés Paz, 2010, p. 20).

Como resultado, casi la mitad de las tierras estatales fueron convertidas en cooperativas, lo que hizo urgente asumir el fortalecimiento de mecanismos de autogestión campesina para que estas entidades estuvieran en capacidad de readecuarse a las nuevas condiciones del sector, entre las cuales se encontraba la intensificación de las relaciones mercantiles, la escasez de recursos e insumos, la contratación de los servicios estatales, entre otros.

Dentro de las decisiones tomadas dentro de la agricultura se incluyó el rediseño y fortalecimiento de un grupo de 500 CCS, a través de la entrega de medios de producción y la realización de nuevas medidas organizativas. Mientras esto sucedía, las CPA sufrían una brusca contracción que redujo su número casi a la mitad de las existentes a mediados de la década anterior.

Desde ese momento y casi hasta inicios de los 2000, el elemento fundamental de la estrategia agraria concebida e implementada en el país fue la conversión de las empresas agropecuarias estatales en empresas de tipo cooperativo, dentro de las estructuras empresariales del Ministerio de la Agricultura, a partir de la entrega de tierras en usufructo a colectivos de trabajadores y el traspaso de los medios de producción e instalaciones. Surgían así las Unidades Básicas de Producción Cooperativa (UBPC), bajo un modelo híbrido de organización que asumía muchos principios del funcionamiento cooperativo, pero se mantenía enmarcada en una 
empresa estatal de manera que esta subordinación condicionaba y presentaba numerosas restricciones a su autogestión y cuyos miembros, provenientes en su mayoría de dinámicas y estructuras de la empresa estatal, adolecían de una conciencia y cultura del cooperativismo, ya que estos habían sido, hasta ese instante, trabajadores agrícolas. (Valdés Paz, 2010, p. 95, 96).

Esto último es un aspecto que, según varias investigaciones no se restringe al ámbito de las UBPC; autores como Echevarría y Pérez (2006) dan cuenta de los procesos socioeconómicos que están incidiendo en que muchas de las incorporaciones a cualquiera de las cooperativas agropecuarias, provengan de trabajadores con experiencias laborales previas en entornos muy alejados de la cultura del cooperativismo. En este sentido, se evidencia la necesidad de concebir e implementar acciones orientadas, tanto a nivel institucional como dentro de las propias cooperativas, a elevar la cultura cooperativa en los productores cubanos que pertenecen a ellas.

Hace algo más de una década, a raíz del proceso de transformación del modelo económico cubano, conocido como Perfeccionamiento del modelo económico y social, el sector agropecuario, y en particular, el cooperativo agropecuario ha estado experimentando nuevas transformaciones. En la actualidad existen propuestas y se ejecutan alternativas que buscan, fundamentalmente, fortalecer y consolidar las cooperativas agropecuarias del país, que se encuentran distribuidas geográficamente en buena parte de la geografía nacional y se agrupan en Cooperativas de Créditos y Servicios (CCS), Cooperativas de Producción Agropecuaria (CPA) y Unidades Básicas de Producción Cooperativa (UBPC).

De acuerdo con los datos aportados por la Dirección Nacional de Desarrollo de cooperativas del Ministerio de la Agricultura de Cuba, en diciembre de 2020 se mantenían activas en el país un total de 4817 unidades productivas cooperativas, distribuidas entre 1485 UBPC; 868 CPA y 2464 CCS. En ellas, trabaja más de medio millón de personas, donde predominan los hombres (más de 400 000) por encima de las mujeres (cuyo número apenas roza los cien mil).

Estas unidades presentan una diversidad relevante en cuanto a tipo de producción pues están presentes en la actividad agrícola, la agroforestal, la azucarera, la ganadera y la tabacalera. También son diversas en cuanto a sus capacidades de producción, al estado de sus infraestructuras, sus capacidades productivas y sus capacidades para incidir de manera positiva en las transformaciones de las comunidades en que se encuentran enclavadas. 


\section{RURALIDAD Y USO SOCIAL DE LAS TIC}

La estructura social del área rural es muy compleja por su heterogeneidad y por la brecha socioeconómica entre productores, incluso, dentro del propio sector cooperativo, donde se perciben profundas situaciones de vulnerabilidad, por ejemplo, en los jóvenes y en las mujeres, estas últimas en franca desventaja respecto a sus pares masculinos.

Los estudios sobre ruralidad en Cuba, y las estadísticas disponibles entre 2008 y 2018, remarcan las desventajas en relación con los contextos urbanos en temas como la vivienda y el hábitat, el acceso a los servicios sociales, los niveles de escolaridad o las desigualdades territoriales, clasistas y económicas, etarias y de género. Estas investigaciones coinciden en la persistencia de patrones adulto-céntricos y androcéntricos para cuya reversión se requieren políticas integrales y holísticas (Hidalgo, 2020).

La brecha de usuarios de internet entre el área urbana y rural es significativa en la mayoría de los países de América Latina que, como promedio, alcanza los 25 puntos porcentuales, y en algunos países llega a los 40 puntos porcentuales (CEPAL, 2021, p. 10). En Cuba, la Encuesta de Indicadores Múltiples por Conglomerados (MICS) realizada en 2019 que recopiló información sobre la exposición a medios masivos y el uso de computadoras e internet entre adolescentes, mujeres y hombres de 15 a 49 años de edad, constata la diferencia territorial de 20 puntos porcentuales en la posesión de teléfonos móviles y de computadoras. (Cuba/MICS, 2020, p. 65)

Específicamente, en la propia indagación se señala que en las urbes cubanas la posesión de un teléfono móvil es de $76.6 \%$ y que en las localidades rurales disminuye a $56.5 \%$; mientras que la relación es de 33,4\% contra un 12,5\% si se apunta a la posesión de computadoras. En otra arista, cuando se les pregunta a las mujeres ${ }^{5}$ si usaron internet durante los últimos 3 meses, la distancia entre áreas urbanas y rurales en Cuba aumenta a un 28,8\%, lo cual demuestra una vulnerabilidad por concepto de género asociada a la brecha digital. (Cuba/MICS, 2020, p. 66)

Para reforzar el estado de la cuestión, aunque las habilidades demandadas por el instrumento apuntan estrictamente a conocer el estado de la alfabetización tecnológica, en cada una de las actividades por las que se pregunta, como mover archivos, enviar correos electrónicos

\footnotetext{
${ }^{5}$ El informe declara que el 46,7\% de las mujeres de áreas urbanas usaron internet en los últimos 3 meses mientras apenas lo hicieron el 17,9\% de las mujeres del área rural (MICS, 2020, p. 66).
} 
con archivos adjuntos o crear una presentación, se sostiene una diferencia siempre en detrimento de las áreas rurales. (Cuba/MICS, 2020, pp. 67-68)

Aun cuando el operador estatal de comunicaciones de Cuba trabaje desde 2017 por introducir y desarrollar las tecnologías de acceso inalámbrico de banda ancha, hasta el momento solo el 4,6\% de las viviendas cubanas disfrutan del servicio Nauta Hogar. En este aspecto también es notoria la diferencia por lugar de residencia que marca la encuesta Cuba/MICS, pues solo el 0,9\% de esos hogares son rurales. En virtud de ello, se ofrece un servicio de conectividad a internet para algunas localidades de zonas rurales a un tercio de lo que cuesta en las ciudades (ETECSA, 2018), pero obviamente este tipo de acciones no satisface la demanda ni es la solución del problema de fondo que, con las actuales limitaciones asociadas a la crisis sanitaria, es más complejo.

Sobre las y los cooperativistas agropecuarios existen varios mitos, subestimaciones y prejuicios en el imaginario social, incluyendo el de su distanciamiento de las herramientas y plataformas digitales. Por ello, es importante abordar los usos de internet y de redes sociales digitales para alcanzar una comprensión más acabada y profunda de las características, formas de comunicación y socialización, necesidades de aprendizaje y formas de producción de información digital que definen e impulsan a este importante sector de la agricultura cubana.

Desde los años 90 del siglo XX, teóricos franceses ${ }^{6}$ advirtieron la importancia de la parte social de la tecnología y colocaron al usuario con un rol activo en la integración de cualquier innovación. De esta forma, crearon la Teoría de Usos Sociales de las TIC, la cual concibe la relación con los aparatos y dispositivos -desde la radio hasta las computadoras y más allá-, en virtud de los contextos económicos, psicológicos, sociológicos, culturales y políticos que determinan al usuario.

De cómo conectan usuarios y tecnología, y de cómo los usos sociales a veces se alejan de las ideas primigenias de los inventores y creadores, se ocupan tres entidades dinámicas e interrelacionadas: el proyecto (la idea de lo que debe ser), el objeto (la herramienta o el artefacto mismo) y la función (lo que se espera en el orden pragmático). Existen, además, distintas modalidades y formas en que se puede presentar el uso de las TIC: conforme, perverso, alternativo, estereotipado, ritual, sustitutivo, etc., todo depende de lo que el usuario realice con

\footnotetext{
${ }^{6}$ Se alude a Perriault y Flichy. Véase: Perriault, Jacques (1991). Las máquinas de comunicar y su utilización lógica. Gedisa editoral. Barcelona y Flichy, Patrice (1993). Una historia de la comunicación moderna. Espacio público y vida privada. Gustavo Gill. Barcelona.
} 
los artefactos, y por eso es tan importante observar su conducta, sin perder de vista la interrelación entre el usuario individual y la comunidad en que se inserta.

Conocer las características del acceso, uso y apropiación que lleguen a hacer los usuarios del sistema de pantallas forma parte de las esencias de la cultura digital en el siglo XXI, marco en el que todas las actividades y procesos están atravesados por la preeminencia de internet y más puntualmente de las redes sociales digitales. Con la actual convergencia mediática y la mezcla entre información, entretenimiento y contenidos educativos, la tesis de Canclini (2019) de que en la nueva sociedad la ciudadanía se concreta a partir del consumo no parece desacertada.

Gracias a la hiperconectividad, se han difuminado los géneros de información que circulan en internet, tanto como las actividades productivas y de consumo, o las concepciones de intimidad y de comunidad. Pero en internet el poder también es injusto y desigual, y ello alcanza a los sistemas de contenidos, a los valores, a los comportamientos e incluso afecta a lo real, a la ciencia y a la verdad.

El rechazo al uso de las redes sociales, por ejemplo, para promover discursos de odio, incitación a la violencia y subversión, fue expresado por la ministra de Comunicaciones de Cuba, Mayra Arevich Marín, en la Conferencia Mundial de Internet 2021, celebrada en la ciudad china de Wuzhen (MICOM, 2021). Esta clara posición política puede favorecer en el corto plazo la generación de estrategias transversales de AMI que sirvan para contrarrestar la difusión de noticias falsas y la tergiversación de la realidad con fines políticos y como una herramienta para las hegemonías coloniales.

El sector de las cooperativas agropecuarias requiere, por el compromiso asignado al desarrollo del país, una intervención cercana y profunda que garantice no solamente la disminución de las barreras para el acceso formal o de infraestructuras, sino para el acceso real a internet. Esto es: es importante romper la barrera psicológica y conseguir el "acceso psicológico o motivacional" (van Dijk, 2005) a plataformas y herramientas que promuevan los valores del cooperativismo y que sirvan para mejorar su funcionamiento y la participación igualitaria de socias y socios desde el momento de la constitución, pero también es necesario romper las barreras de las habilidades para que todas y todos los cooperativistas agropecuarios cubanos puedan usar internet cuando lo consideren. Estas limitaciones, sin embargo, se enmarcan apenas en la primera brecha digital, conceptualización que aparece en la literatura desde los años 90 del siglo pasado. 
Como internet continúa jugando un papel importante en las desigualdades de la sociedad de la información, se alude a una segunda brecha digital que, además de contemplar las conocidas barreras materiales, motivacionales o de habilidades, implica a las tipologías de uso, o sea, aquellas que permiten tomar la iniciativa a la hora de buscar, seleccionar, integrar, valorar y aplicar información con la intención de mejorar la posición en la sociedad, para lo cual es importante el tiempo, la variedad y sobre todo, la finalidad del uso de internet (Van Dijk, 2005).

El estudio de los usos de internet en el sector de las cooperativas agropecuarias cubanas, desde la perspectiva de la segunda brecha digital, permitirá dilucidar, en síntesis, las consecuencias, positivas o negativas, que tienen para las vidas de socias, socios y familiares. Sin embargo, más allá de las complejidades metodológicas que suponga en su día ese ejercicio, lo importante ahora es trabajar aceleradamente en visibilizar las singularidades del sector y la diversidad de los contextos donde producen resignificaciones sociales, alcanza objetivos y concretan proyectos.

\section{ELEMENTOS METODOLÓGICOS}

Los estudios sobre usos de internet en Cuba se han enfocado en varios sectores sociales, como adolescentes y jóvenes, profesores y estudiantes universitarios, y población urbana. De momento, no se ha identificado un acercamiento al tema en el sector cooperativista agropecuario, aun cuando sus miembros superan el medio millón de personas. Todo parece indicar que no se les considera utilizadores intensivos, autónomos y críticos de las TIC.

Este estudio corresponde a la fase de diagnóstico del proyecto "Gestión de contenidos multiplataforma destinados al trabajo con las cooperativas agropecuarias cubanas" y fue desarrollado como una investigación de campo ante la necesidad de conocer las características de la audiencia potencial e identificar los contextos socioculturales que les son propios, como paso previo al diseño de la arquitectura web y la producción de contenidos hipermedia.

Para la realización del diagnóstico, se optó por un enfoque de investigación cuantitativo con un diseño no experimental, descriptivo y transversal, mediante la aplicación de una encuesta en línea a una muestra no intencional, en virtud de las condiciones impuestas por la pandemia y por la dispersión geográfica de las y los cooperativistas agropecuarios.

Para ser consecuente con el contexto y que se ofreciera información desde las capacidades y habilidades tecnológicas de los sujetos de estudio, se utilizó la herramienta 
Google forms (https://docs.google.com/forms/u/0/) como soporte del cuestionario. Sus requisitos son básicos: se requiere contar con conexión a internet, tener una cuenta de Google y un navegador web. Con este programa gratuito, de interfaz amigable y fácil de acceder desde cualquier dispositivo, la creación y publicación del formulario fue simple. Gracias a esta herramienta, se dio seguimiento a las estadísticas de respuesta en tiempo real, se obtuvieron representaciones gráficas automáticas, fue posible compartir el cuestionario por correo y se garantizó la fiabilidad de los resultados.

Esta manera de administrar el cuestionario, sin embargo, obligó a concebir un sistema de ayuda a través de las escuelas ramales del Ministerio de la Agricultura (ERMA) para incentivar su utilización y esclarecer dudas de cooperativistas a lo largo del país. Como resultado de esta colaboración, la tasa de respuesta superó las expectativas de los investigadores.

El diseño del cuestionario, relativamente breve, se centró en aspectos sobre los que realmente no existía información. En consecuencia, tampoco se conoce la evolución ni puede predecirse el comportamiento del uso de internet en el sector cooperativo agropecuario cubano.

La población de referencia son todas y todos los cooperativistas agropecuarios cubanos, independientemente del tipo de brecha digital al que están sometidos. La muestra de referencia es aquella que se conecta a internet, por tanto, los datos no son extrapolables a todo el universo de cooperativistas agropecuarios cubanos. Con todo, esta investigación aporta una visión, si bien básica y con finalidad específica, sobre la incorporación de la cultura digital en el sector, lo cual la convierte en un trabajo de referencia para futuras investigaciones.

Con este diagnóstico se obtuvo información relativa a:

a) Las posibilidades de conexión y acceso, representadas en la infraestructura tecnológica.

b) Las modalidades de hábitos y usos, representadas en las rutinas y prácticas de consumo.

c) Las características de los contenidos y acciones de comunicación, representadas en las herramientas, plataformas y fuentes de información, así como las formas de socialización. 


\section{RESULTADOS Y DISCUSIÓN}

La encuesta constó de 25 preguntas y fue completada por 1621 cooperativistas en un plazo de 30 días. El enlace del cuestionario fue distribuido por los canales de comunicación interna del Ministerio de la Agricultura de la República de Cuba. El 56\% de las preguntas son de tipo cerrada y el $44 \%$ son de opción múltiple. Solo en dos casos aparecen preguntas tipo matriz. La resolución de la encuesta supone un bajo esfuerzo para las y los encuestados, los cuales pueden completarla totalmente, con una conectividad aceptablemente buena, poco menos de 10 minutos. La encuesta se organiza en tres bloques de interés, a saber:

a) Datos generales

Esta sección se concentra en información de tipo sociodemográfica que describe estadísticamente al sector analizado. En todos los casos, solo existe una posibilidad de respuesta. Se consideraron las siguientes variables e indicadores:

- Género (femenino, masculino, otro)

- Edad (rangos etarios: 14 - 26 años; 27- 59 años; 60 años o más)

- Tipos de cooperativas (UBPC, CCS, CPA)

- Provincia (15 provincias y un municipio especial).

- Municipio (este indicador es abierto, con la expectativa de declarar alguno de los 159 municipios)

- Localidad (este indicador es abierto, con la expectativa de declarar los núcleos de población con identidad propia, como los consejos populares)

b) Acceso a internet

Esta sección busca identificar el lugar, las vías y los dispositivos para la conexión a internet, así como el tiempo y los lugares de conexión que más emplean las y los cooperativistas agropecuarios. A excepción de la frecuencia y el tiempo, es posible y hasta deseable declarar en las respuestas más de una opción. Se consideraron las siguientes variables e indicadores:

- Frecuencia de conexión (diariamente, de vez en cuando, semanalmente, mensualmente, nunca)

- Tiempo de permanencia (menos de 1 hora, entre 1 y 3 horas, entre 3 y 5 horas, más de 5 horas)

- Personas conectadas en el hogar (yo, mi esposa o esposo, mis hijos, otros) 
- Lugares de conexión (desde la casa, desde lugares públicos, desde la cooperativa, desde la escuela, desde la universidad, desde el Joven Club, otros)

- Vías de conexión (Wiffi, Nauta Hogar, datos móviles, otra)

- Dispositivos para la conexión (PC, celular, laptop, tableta, reloj inteligente, otro)

- Características del celular (básico, medio, Smartphone, no tiene)

- Horarios de conexión (mañana, tarde, noche, madrugada)

c) Usos y hábitos

Esta sección explora las actividades digitales desarrolladas por las y los encuestados cuya principal característica es que se ejecutan simultáneamente. Se pregunta por el tipo de información buscada, las acciones en las redes sociales y la información compartida como forma de acercarse a ciertas rutinas o prácticas de uso. Se consideraron las siguientes variables e indicadores:

- Herramientas y servicios de internet (redes sociales, servicios de alerta de noticias, correo, bases de datos en línea, herramientas de video en línea, descargar aplicaciones, blogs, foros, chat de Messenger)

- Sitios más visitados (Google, Facebook, Yahoo, etc.)

- Información buscada en internet (de entretenimiento, para estudiar y trabajar, política, noticias, etc.)

- Acciones más comunes en redes sociales (actualizar, escribir, visitar, leer, etc.)

- Información compartida en los sitios de redes sociales (artículos, videos, música, etc.)

\section{a) Análisis de los datos generales}

\section{Género}

La mayoría de los respondientes $(66,13 \%)$ son del género masculino, mismo que predomina entre los socios de las cooperativas agropecuarias. La mirada de género es importante para estudiar las situaciones de vulnerabilidad en las mujeres por menor acceso a internet. Específicamente en el sector agropecuario, las mujeres no destacan en los niveles superiores de dirección y tampoco tienen mayor control de las tecnologías que los hombres. Leyva (2018) afirma que la participación de las mujeres en las cooperativas es 
mayoritariamente como esposas, hijas u otros parientes de cooperativas, no como empoderadas económicas.

\section{Rango etario}

El análisis por edad arroja que el 88,27\% de los respondientes se encuentran en la etapa adulta (entre 27 y 59 años), lo cual se corresponde a las edades de quienes integran las juntas directivas de las cooperaticas agropecuarias. Una revisión al interior de esa franja -en orden descendiente-, destaca que casi la mitad de los adultos $(706,49,3 \%)$ tienen entre 46 y 59 años, seguido por quienes tienen entre 36 y 45 años $(505,35,29 \%)$ y por quienes tienen entre 27 y 35 años $(220,15,37 \%)$. Es preciso atender el estado de la población más vulnerable, como los adultos mayores $(4,9 \%)$ y los jóvenes $(6,6 \%)$, los cuales son los menos representados. Las estrategias de desarrollo de las cooperativas agropecuarias precisan de la sabiduría acumulada por los primeros y del necesario relevo de los segundos.

\section{Tipos de cooperativas}

Según el Resumen Nacional de Unidades Productoras (MINAG, 2019), en Cuba existen 4826 cooperativas. En tanto las CCS son el tipo de cooperativa más numerosa en el país, también son las más representadas en esta encuesta, con el 42,07\%. Sin embargo, se advierte que las UBPC, que son las más dotadas en TIC, son las menos representadas $(23,44 \%)$, lo cual levanta suspicacias respecto al aprovechamiento de internet. Por el contrario, las CPA ocupan el segundo lugar en la representatividad $(34,48 \%)$ aun cuando son las menos numerosas.

\section{Territorio y zonas geográficas}

- En virtud de la contribución de las cooperativas agropecuarias al desarrollo local desde los territorios, es importante analizar la distribución territorial en el uso de internet. Con mucho, la provincia más representada es Santiago de Cuba $(25,23 \%)$ y la menos representada es Mayabeque $(0,24 \%)$. Esto es consistente con el número de cooperativas existentes, pues Santiago de Cuba es una de las tres con mayor número de cooperativas en el país, mientras La Habana y la Isla de la Juventud son las que menor número de cooperativas tienen. Sin embargo, la pobre representatividad de Holguín (3,57\%) y 
Granma $(9,56 \%)$ es inconsistente con la cantidad de cooperativas en esos territorios. Aun cuando Villa Clara aparece en tercer lugar, apenas representa el 9,68\% cuando es la cuarta provincia con mayor número de cooperativas en el país. En cuanto a las zonas geográficas, la encuesta reporta una mayor representividad de la zona oriental, seguida por el centro y luego por occidente, lo cual es consistente con el número de cooperativas existentes, según MINAG (2019).

\section{b) Análisis del acceso a internet}

Gráfico 1: Frecuencia de conexión a internet

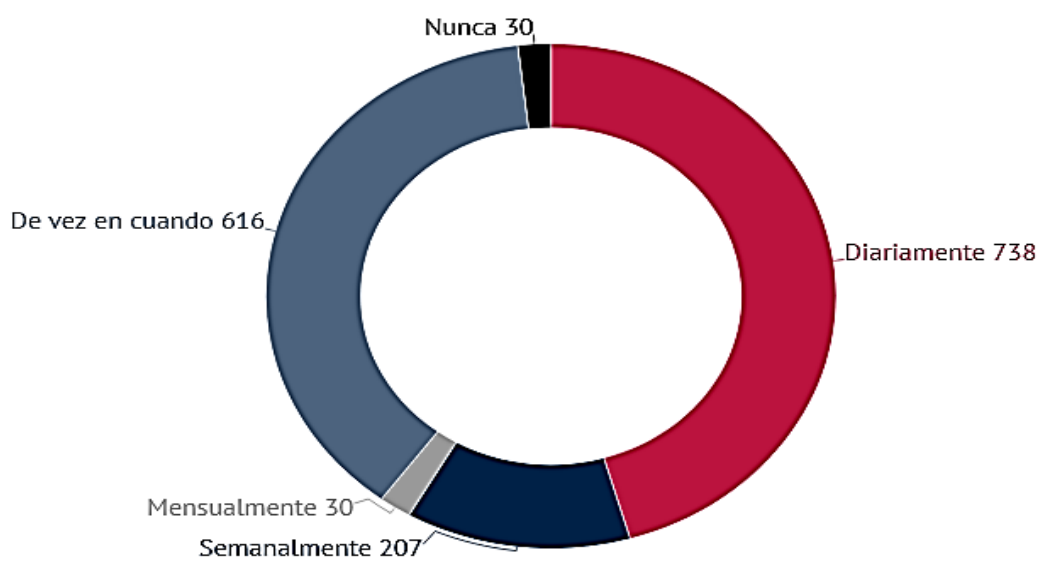

Fuente: resultados de la encuesta de uso digital de cooperativistas agropecuarios (2021).

\section{Frecuencia de conexión}

La frecuencia de conexión expresa permite conocer si el uso de internet es o no regular. Los resultados se expresan positivamente, pues el $45,52 \%$ se conecta diariamente, por lo que puede afirmarse que se usa regularmente internet en el ámbito cooperativo agropecuario. Sin embargo, la diferencia entre quienes se conectan diariamente y quienes se conectan de vez en cuando es muy corta, apenas 122 respondientes (7,52\%). La brecha digital es evidente en el $1,85 \%$ que nunca se ha conectado y en un por ciento idéntico que se conecta mensualmente, pero también entre quienes responden que se conectan semanalmente $(12,7 \%)$. En total, la primera brecha digital se evidencia en el $12,76 \%$ de los encuestados. 
El análisis de la frecuencia de conexión por género, por su parte, alerta la situación de clara desventaja para las mujeres y recomienda un análisis en profundidad sobre este tema que, además, corrija el potencial sesgo muestral.

Gráfico 2: Frecuencia de conexión por género

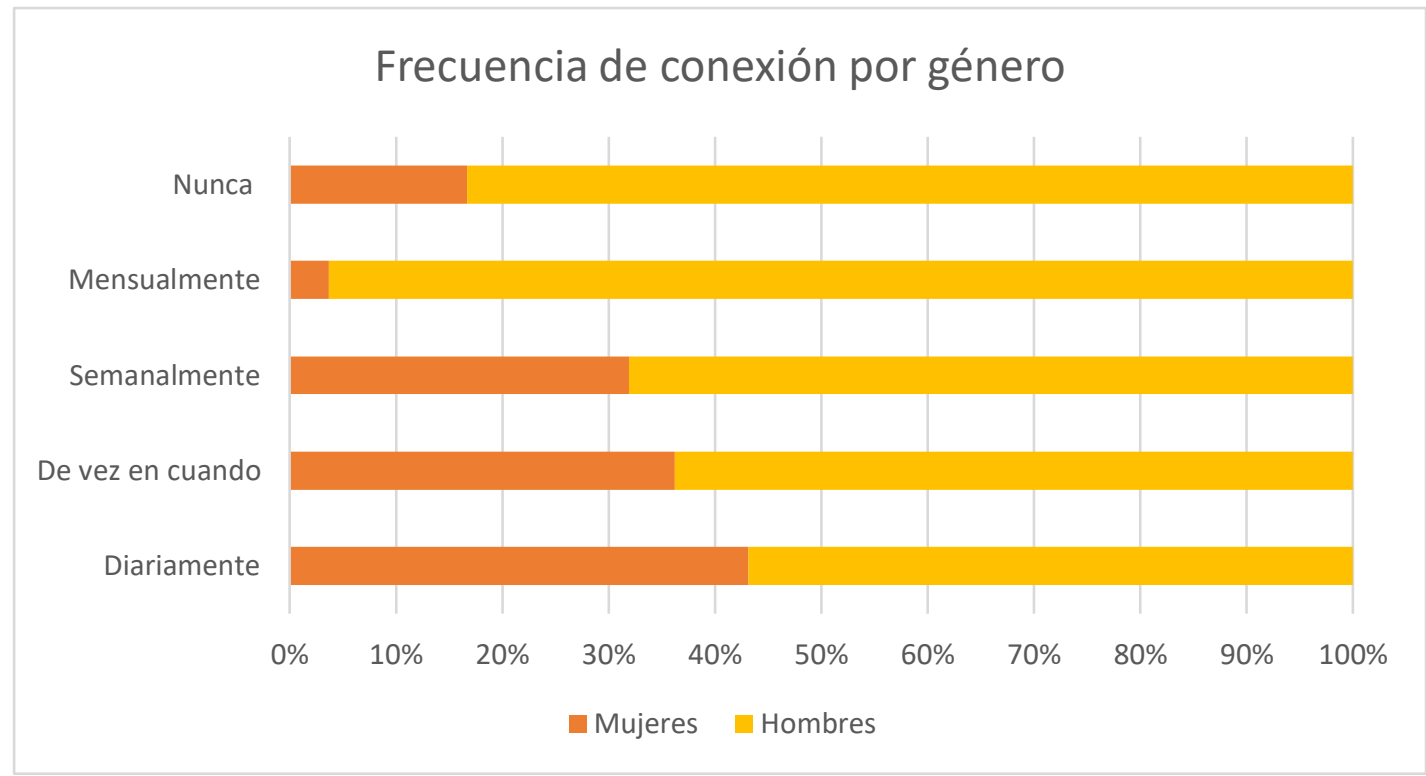

Fuente: Resultados de la encuesta de uso digital de cooperativistas agropecuarios (2021).

\section{Tiempo de conexión}

La permanencia en internet responde al rango temporal que se establece entre quienes se conectan menos de una hora $(53,6 \%)$ y los que se conectan entre 1 y 3 horas $(40,77 \%)$, lo cual parece lógico en un sector que dedica gran parte su tiempo al trabajo en el campo. Sin embargo, estos resultados deben verificarse en una triangulación con indicadores asociados al costo de los datos móviles y al estado de la conectividad en las zonas rurales para verificar si el tiempo de conexión está asociado al tiempo libre o a la informatización de la sociedad. 
Gráfico 3: Tiempo de conexión

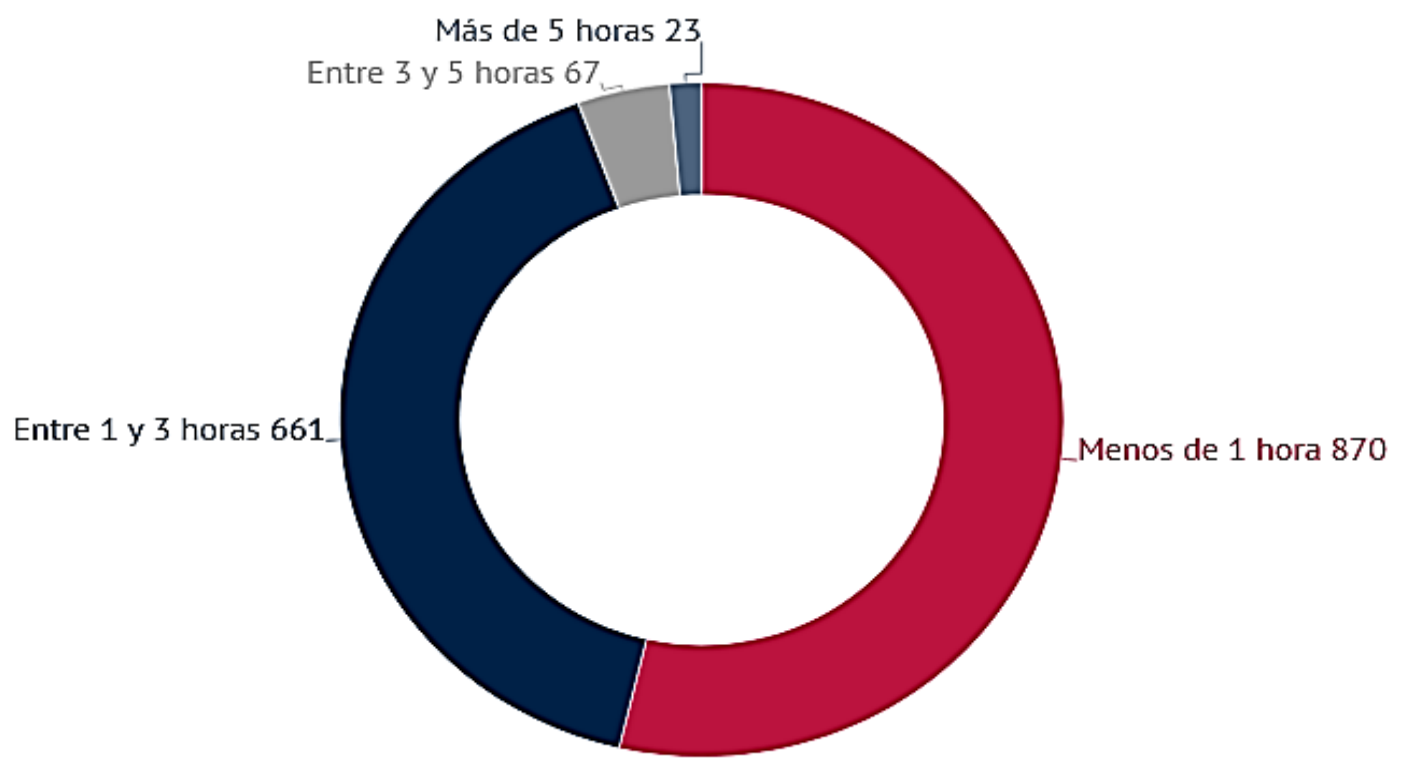

Fuente: Resultados de la encuesta de uso digital de cooperativistas agropecuarios (2021)

El análisis del tiempo de conexión por género evidencia que, aun cuando las mujeres se conectan con menos frecuencia que los hombres, pueden permanecer más tiempo conectadas que ellos, como promedio entre 3 y 5 horas.

Gráfico 4: Tiempo de conexión por género

\section{Tiempo de conexión por género}

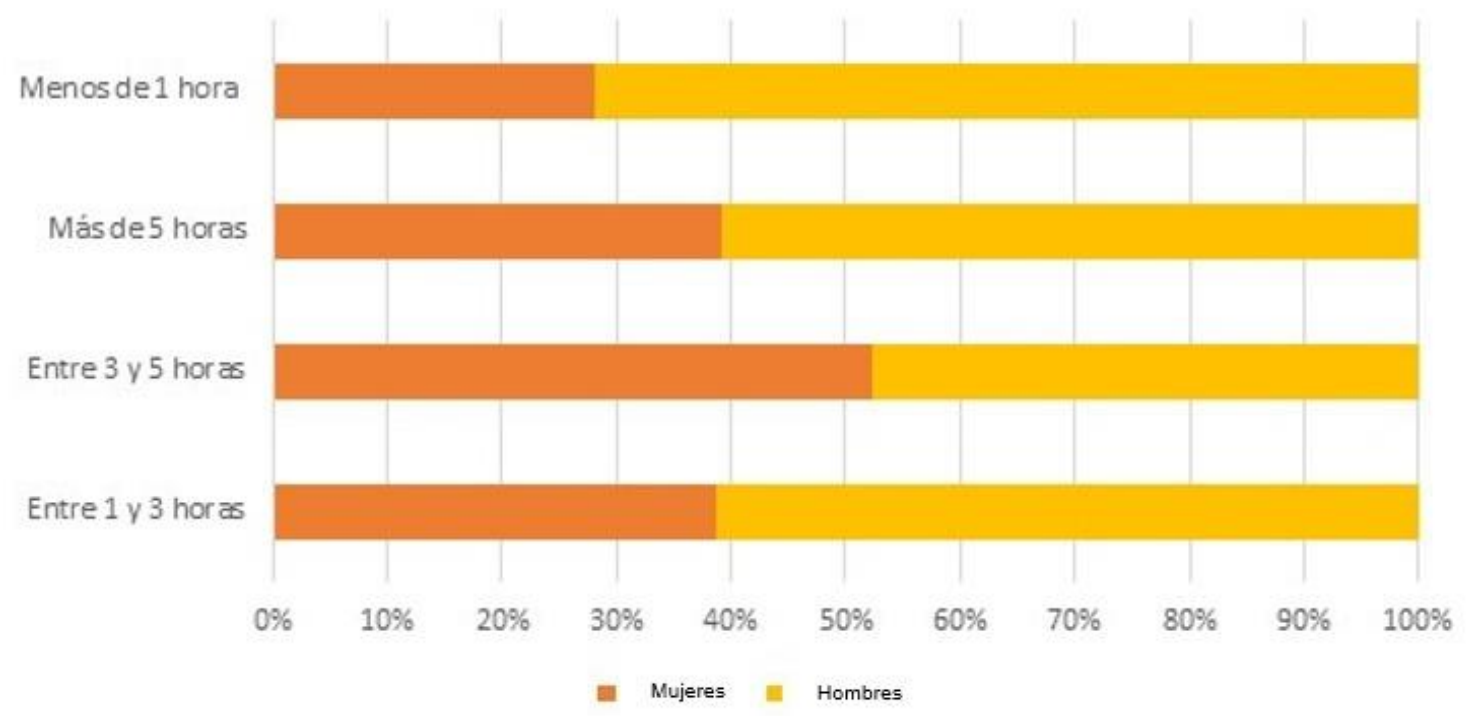

Fuente: Resultados de la encuesta de uso digital de cooperativistas agropecuarios (2021) 


\section{Horarios de conexión}

La noche y la tarde son los horarios que se utilizan mayormente para la conexión a internet. Si se piensa en estrategias de redes sociales para el sector cooperativo agropecuario se deberá adecuar los horarios de publicación a este rango horario.

Gráfico 5: Horarios de conexión

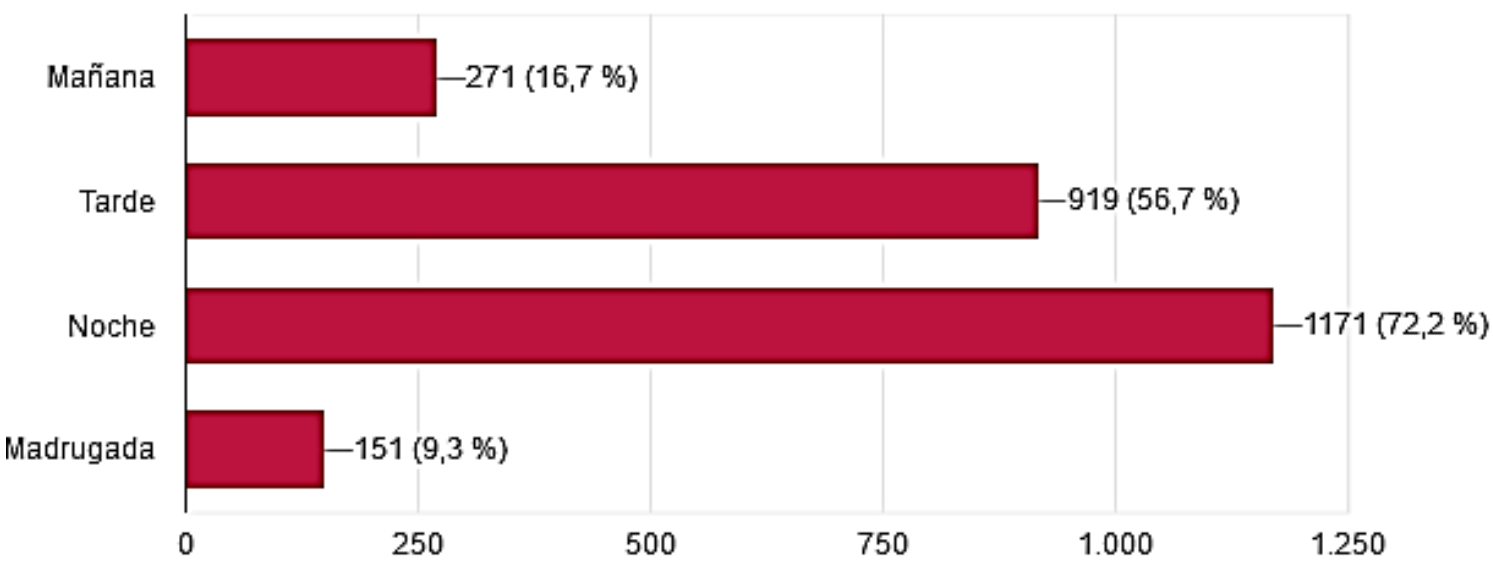

Fuente: Resultados de la encuesta de uso digital de cooperativistas agropecuarios (2021).

\section{Personas conectadas en el hogar}

En Cuba, existe la tendencia de que se conecten en el hogar varios miembros de la familia. Se confirma en este diagnóstico que en el $88.46 \%$ de los casos, los hijos de los cooperativistas se conectan en sus hogares. Si se analiza el rango etario más representativo en la encuesta, los hijos que se conectan deben ser jóvenes de la llamada generación z.

\section{Lugares de conexión}

Una amplia mayoría $(85,07 \%)$ de las y los encuestados se conecta desde casa. Teniendo en cuenta la baja disponibilidad de computadoras y de telefonía fija en el ámbito rural, conectarse desde casa y desde lugares públicos alude con seguridad a la capacidad del sector cooperativo para utilizar datos móviles. Las cooperativas apenas representan un lugar de 
conexión para el 4,99\%, lo cual es indicativo del bajo nivel de transformación digital en las oficinas del sector cooperativo.

\section{Vías para conectarse a internet}

Esta respuesta se correlaciona con la anterior y refuerza el criterio sobre el uso de internet a través de datos móviles, el cual es declarado por el 86,05\% de las y los encuestados.

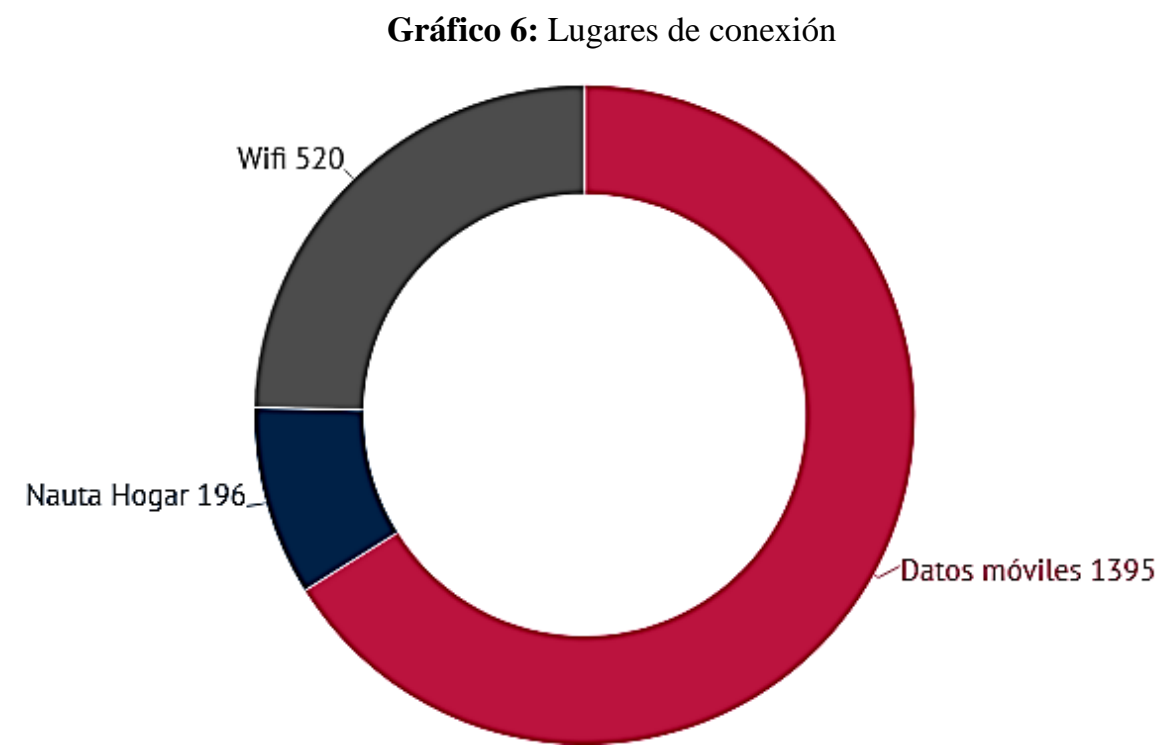

Fuente: Resultados de la encuesta de uso digital de cooperativistas agropecuarios (2021).

\section{Dispositivos para la conexión}

La mayoría $(92,48 \%)$ declara utilizar los dispositivos móviles para acceder a internet. En menor medida aparecen las computadoras, laptops y tabletas que tienen muy baja representatividad. Las estrategias y campañas de comunicación, así como los contenidos de la multiplataforma deberán pensarse en primer lugar en las dimensiones móviles. 
PontodeAcesso: Revista do Instituto de Ciência da Informação da UFBA DOI: https://doi.org/10.9771/rpa.v15i3.47475

Gráfico 7: Dispositivos para la conexión

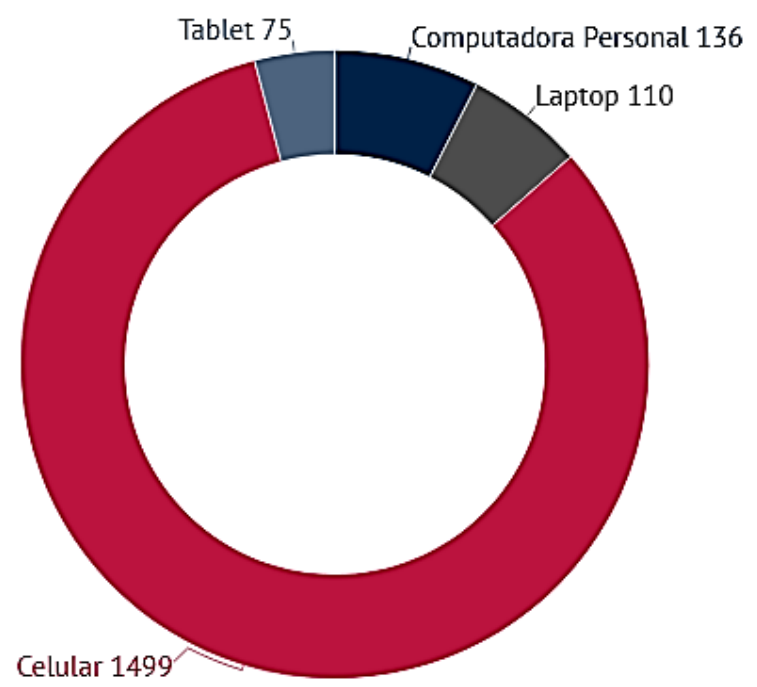

Fuente: Resultados de la encuesta de uso digital de cooperativistas agropecuarios (2021).

\section{Telefonía móvil}

La muestra representada accede a tecnologías medias y altas lo cual facilita la navegación y el uso de herramientas y plataformas digitales. El 42,19\% refiere contar con dispositivos óptimos para el uso de internet.

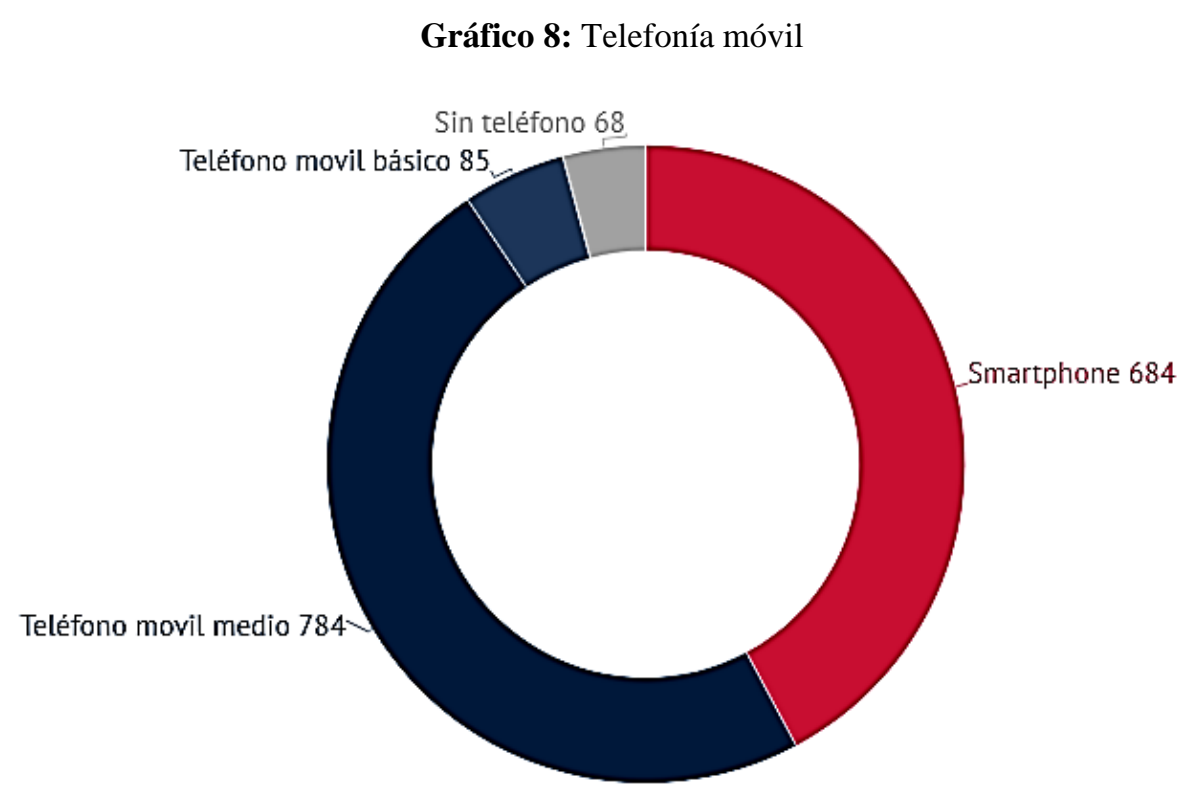

Fuente: Resultados de la encuesta de uso digital de cooperativistas agropecuarios (2021). 


\section{c) Análisis de los usos}

\section{Usos habituales de internet}

Entre los usos más representativos se declaran una veintena de actividades. En primer orden se destaca chatear y utilizar las redes sociales. Esto denota capacidades comunicativas en el sector cooperativo agropecuario y la importancia que le conceden a las relaciones interpersonales. En un segundo orden se destaca trabajar, descargar aplicaciones y leer, revisar el correo y comprar. Llama la atención que se declare explícitamente buscar información científica en el punto medio de los usos.

Gráfico 9: Usos habituales de internet

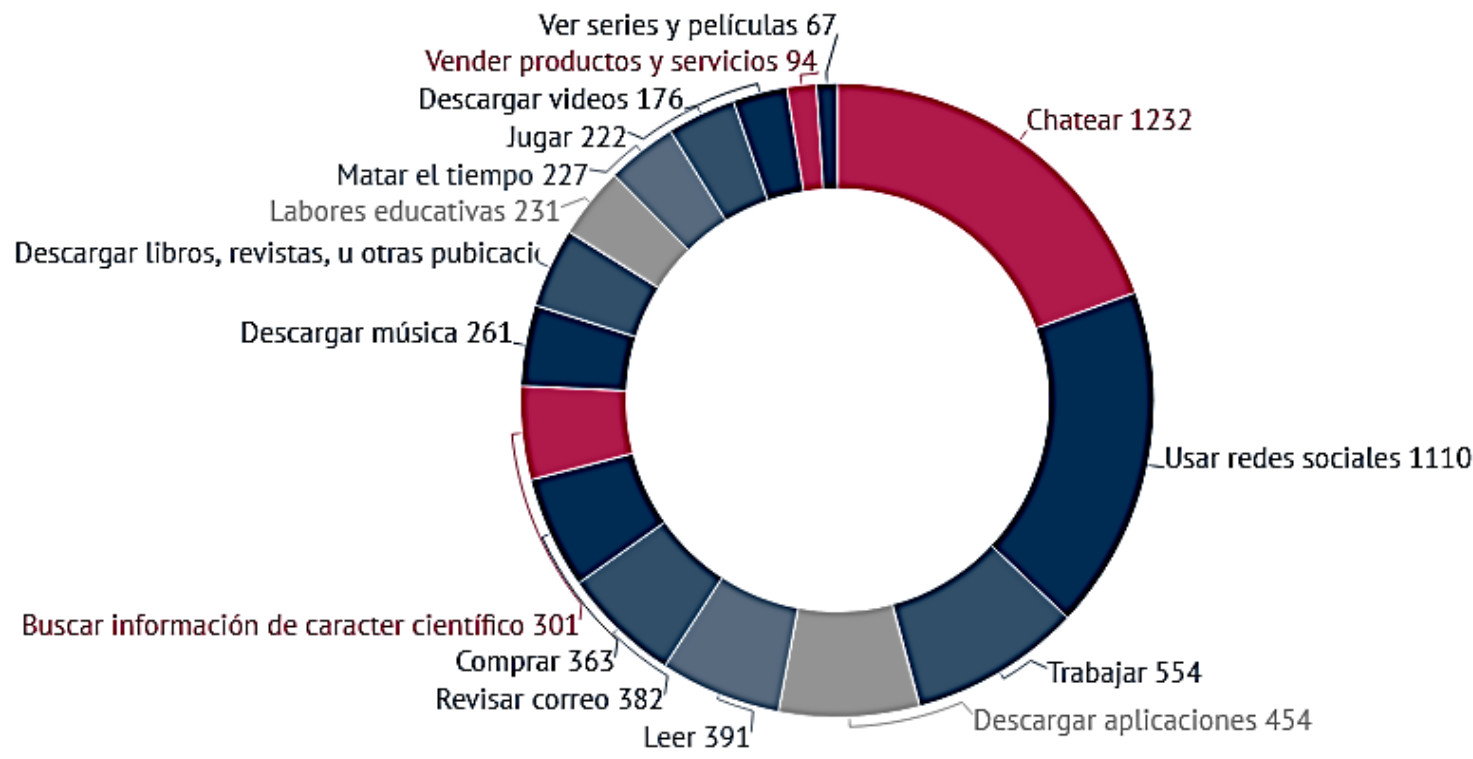

Fuente: Resultados de la encuesta de uso digital de cooperativistas agropecuarios (2021).

\section{Herramientas y servicios de internet}

Las redes sociales y el Messenger lideran las herramientas preferidas para la comunicación. Las descargas de aplicaciones y el correo son las herramientas más utilizadas por las y los cooperativistas. 
Gráfico 10: Herramientas y servicios de internet

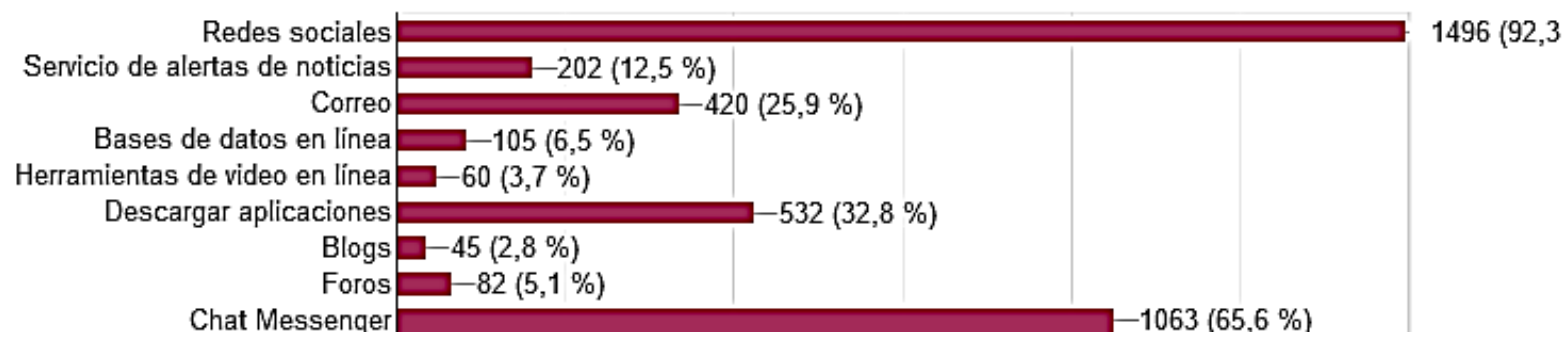

Fuente: Resultados de la encuesta de uso digital de cooperativistas agropecuarios (2021)

\section{Sitios más visitados}

Se declara a Facebook y Google como los entornos más visitados. Llama la atención el uso de redes sociales específicas como LinkedIn y escenarios alternativos para la visualización de videos como Vimeo.

Gráfico 11: Frecuencia de uso de los sitios más visitados
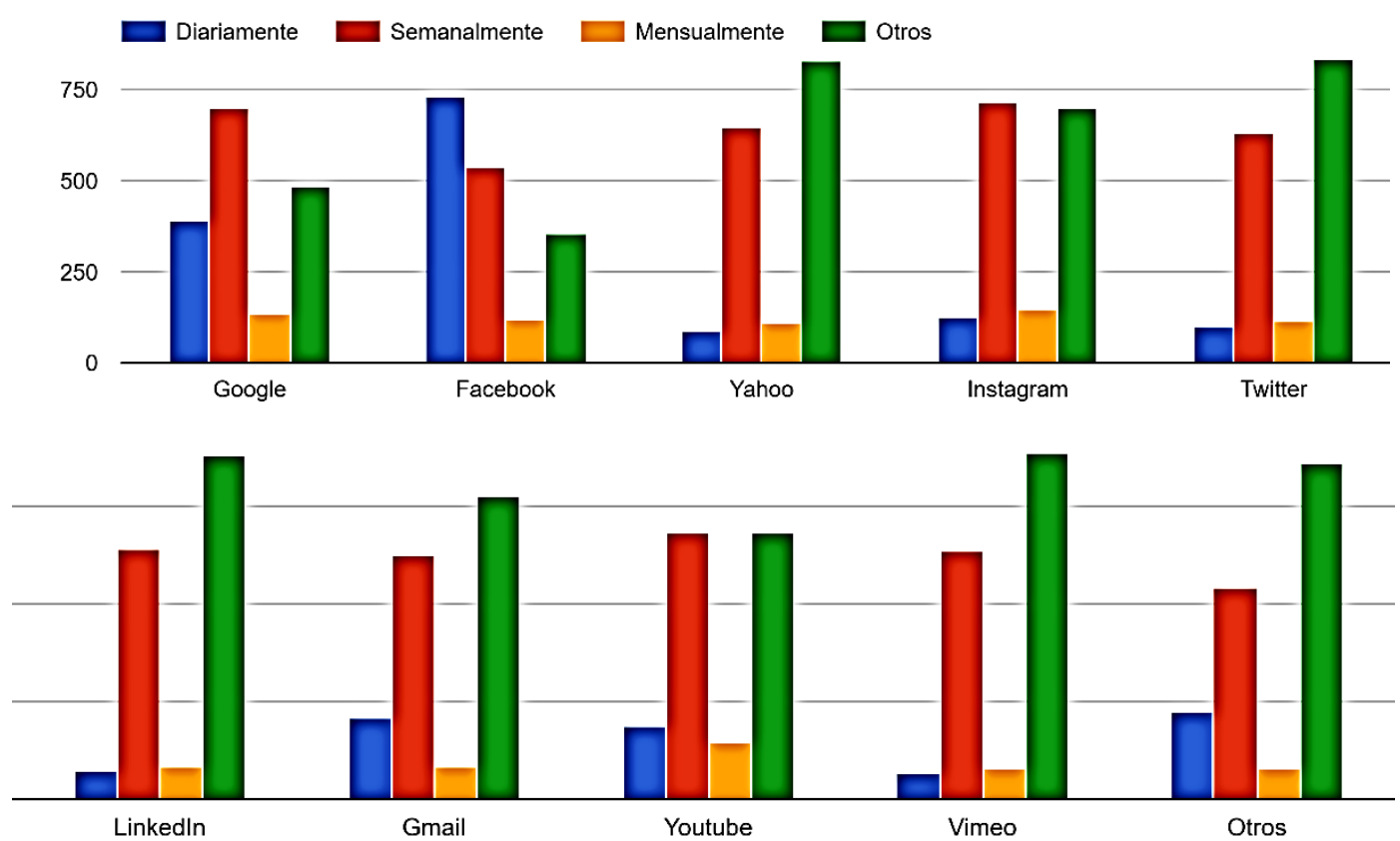

Fuente: Resultados de la encuesta de uso digital de cooperativistas agropecuarios (2021). 


\section{Información buscada en internet}

La información de entretenimiento, las noticias y la información escolar y profesional marcan la tendencia en cuanto a las búsquedas que realizan las y los participantes. Se destaca también el interés por la información política y la asociada a los trámites. En ningún caso se explicita la búsqueda de información relacionada con la producción agropecuaria, por lo que habría que profundizar en lo que se considera "información para trabajar".

Gráfico 12: Información buscada en internet

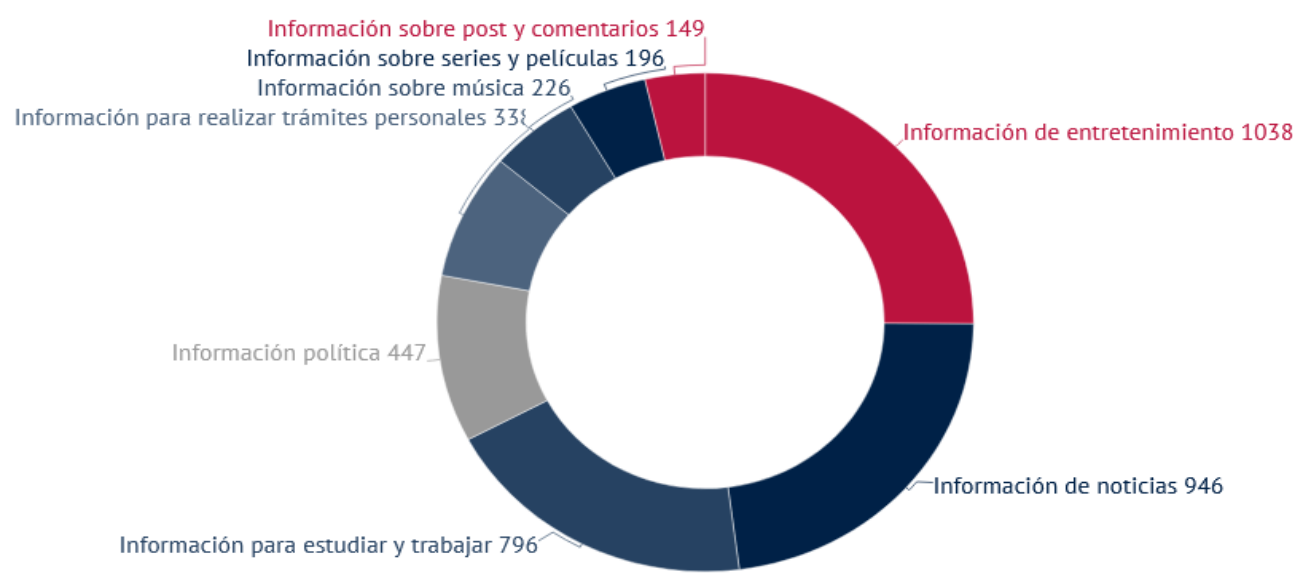

Fuente: Resultados de la encuesta de uso digital de cooperativistas agropecuarios (2021).

\section{Acciones en redes sociales digitales}

El uso de internet para la comunicación interpersonal constituye la práctica más común en las y los respondientes. Informarse del estado de los contactos y actualizar el propio también son acciones consideradas. 
Gráfico 13: Acciones en redes sociales digitales

\section{Preguntar sobre productos antes de la compra \\ Visitar perfil de instituciones Escribir comentarios \\ Publicar fotos Informarme de noticias \\ Actualizar mi estado \\ Escribir mensaje a mis amigos/chatear Leer publicaciones \\ Ubicar a compañeros/amigos que no veo hace tiempo \\ Unirme a grupos de intereses comunes o pasatiempos \\ Saber que están haciendo mis amigos}

Fuente: Resultados de la encuesta de uso digital de cooperativistas agropecuarios (2021).

\section{Socialización de información y contenidos}

La acción de compartir caracteriza la identidad digital de personas e instituciones. Las y los encuestados usualmente comparten publicaciones de redes sociales, fotografías, música o video.

Gráfico 14: Socialización de información y contenidos

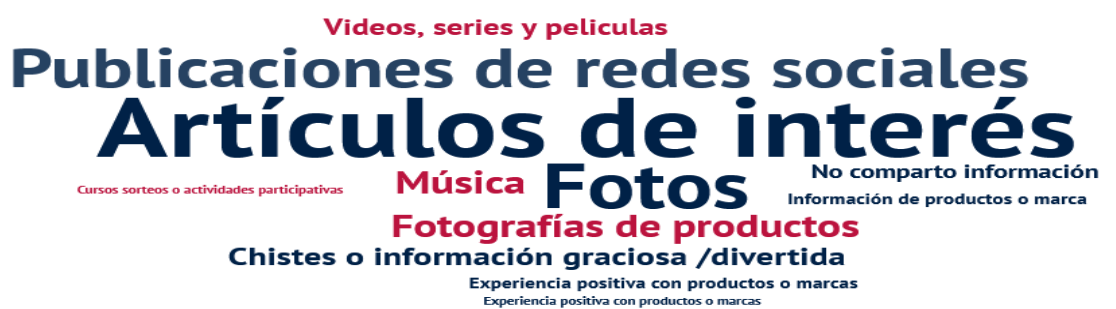

Fuente: Resultados de la encuesta de uso digital de cooperativistas agropecuarios (2021).

\section{CONCLUSIONES}

En el diagnóstico sobre el uso y acceso que hace de internet el sector agropecuario se aprecia, desde el punto de vista sociodemográfico, una participación marcadamente masculina que ratifica el estado de desigualdades de género en los entornos rurales. Por esta razón, se sugiere atender prioritariamente, además de las brechas económicas, laborales y otras conocidas, la brecha digital de las mujeres en el sector cooperativo. Por otra parte, la insuficiente participación de los jóvenes sugiere una atenta mirada a la presencia y acciones desempeñadas por parte de sujetos que se encuentren en esta franja etaria. El marcado interés demostrado en este instrumento por cooperativistas de la zona oriental del país sugiere diseñar 
productos y servicios infocomunicacionales desde las experiencias, percepciones y contribuciones que caracterizan a esos territorios, a sus cooperativistas y familiares.

En cuanto al acceso a internet se demuestra que la frecuencia es regular, básicamente diaria, doméstica, fundamentalmente nocturna y a partir de los datos móviles. Los dispositivos móviles cuentan con las prestaciones para el acceso a internet y para interactuar con eficiencia con las plataformas y herramientas de su preferencia. En la muestra representada se priorizan los aspectos de socialización en el uso de las redes y es notable la mención a compartir, lo cual significa que es importante para las y los cooperativistas mantener el contacto con amigos y otros usuarios y trasladar sus ideas y sentimientos.

Se advierte la imperiosa necesidad de generar una estrategia de creación y fortalecimiento de la vida web para este sector que permita a las y los cooperativistas usar información, dialogar y compartir conocimientos a través de estas plataformas digitales. Con los datos que revela esta encuesta se puede confirmar que existe una notable incongruencia entre el uso de internet que ocurre a nivel individual por parte de las y los cooperativistas y la presencia en internet de las cooperativas agropecuarias.

\section{REFERENCIAS}

1. CEPAL (2021). Datos y hechos sobre la transformación digital. Disponible en: https://www.cepal.org/sites/default/files/publication/files/46766/S2000991_es.pdf

2. Constitución de la República de Cuba. (2019). Disponible en: https://www.granma.cu/file/pdf/gaceta/Nueva\%20Constituci\%C3\%B3n\%20240\%20K B-1.pdf

3. Cuba/MICS (2020). Cuba Encuesta de Indicadores Múltiples por Conglomerados 2019, Informe de resultados de la encuesta. La Habana, Cuba. Dirección de Registros Médicos y Estadísticas de Salud. MINSAP y UNICEF Cuba. Disponible en: https://temas.sld.cu/estadisticassalud/files/2021/02/MICS6_Cuba2019_compressed.pdf

4. ETECSA (2018, 22 de octubre). Oferta especial del servicio nauta Hogar en zonas rurales del país. Disponible en:

http://www.etecsa.cu/inicio/oferta_especial_del_servicio_nauta_hogar_en_zonas_rural es_del_país_2018_10_22/

5. FAO (2017). Information and Communication Technology (ICT) in Agriculture: A Report to the G20 Agricultural Deputies. Rome: FAO. Disponible en: https://www.fao.org/3/a-i7961e.pdf 
6. García Canclini, N. (2019). Ciudadanos reemplazados por algoritmos. Calas. Disponible en:

http://www.calas.lat/sites/default/files/garcia_canclini.ciudadanos_reemplazados_por_ algoritmos.pdf

7. Hernández Morales, A. y Arteaga Hernández, C.M. (2013). Gestión integral cooperativa. Guía para formadores y facilitadores, MINAG, La Habana. Disponible en: http://www.actaf.co.cu/biblioteca/cooperativismo/gestion-integral-cooperativaguia-para-formadores-y-facilitadores.html

8. Hidalgo, V. (2020). Desigualdades, ruralidad e interseccionalidad: análisis del contexto cubano 2008-2018. FLACSO-Cuba: Acuario. Disponible en: http://biblioteca.clacso.org/Cuba/flacso-cu/20201103114047/9-Desigualdadesruralidad.pdf

9. Leyva, A. y Arias, M. (2018). Cuba: Reproducción y estructura social del campesinado. Desafíos para las políticas agrarias y rurales. Disponible en: https://www.google.com/url?sa=t\&rct=j\&q=\&esrc=s\&source=web\&cd=\&ved=2ahU KEwjJi8nd2MD0AhVuRTABHf6aDWEQFnoECB0QAQ\&url=http\%3A\%2F\%2Fsoc iologia-alas.org\%2Facta\%2F2015\%2FGT-

05\%2FCuba\%2520reproducci\%25C3\%25B3n $\% 2520 \mathrm{y} \% 2520$ estructura $\% 2520$ social $\%$ $2520 \mathrm{del} \% 2520$ campesinado $\% 2520 \mathrm{des}$ f $\% 25 \mathrm{C} 3 \% 25$ ADos\%2520para\%2520las $\% 2520$ pol\%25C3\%25ADticas\%2520agrarias\%2520y\%2520rurales.docx\&usg=AOvVaw2oT nJWoCldLgabdT4jDiBI

10. Lineamientos de la Política Económica y Social del Partido y la Revolución para el período 2016-2021 (2016). Disponible en:

http://www.granma.cu/file/pdf/gaceta/01Folleto.Lineamientos-4.pdf

11. MICOM (2021, octubre 12). \#Cuba participa en la Conferencia Mundial de Internet 2021. Disponible en: https://www.youtube.com/watch?v=6YSIU4CWVk4

12. MINAG (2019). Resumen Nacional de Unidades Productoras. Disponible en: https://www.minag.gob.cu/node/2013

13. MINAG (2020). Plan de soberanía alimentaria y educación nutricional de Cuba.

14. ONEI (2021). Tecnología de la información y las comunicaciones. Indicadores seleccionados. Enero-Diciembre 2020. Disponible en:

http://www.onei.gob.cu/sites/default/files/tic_2020_0.pdf

15. Pérez Rojas, N. y Echevarría León, D. (2006). Las Unidades Básicas de Producción Cooperativa cubanas (1993-2003). Disponible en:

http://bibliotecavirtual.clacso.org.ar/ar/libros/grupos/gram/C09RojasLeon.pdf 
16. Sandoval, L.R. (2019). La apropiación de tecnologías en América Latina: una genealogía conceptual. Virtualis, Revista de cultura digital, n.10, 19. Disponible en https://www.revistavirtualis.mx/index.php/virtualis/article/view/296

17. Trendov, N., Varas, S. \& Zeng, M. (2019). Tecnologías digitales en la agricultura y las zonas rurales. Documento de orientación. Disponible en: https://www.fao.org

18. UNCTAD (2021). Informe sobre la Economía Digital 2021. Disponible en: https://unctad.org/system/files/official-document/der2021_overview_es_1.pdf

19. UNESCO (2013). Media and information literacy: policy and strategy guidelines. Disponible en: https://unesdoc.unesco.org/ark:/48223/pf0000225606

20. Valdés Paz, J. (2010). Los procesos de organización agraria en Cuba 1959-2006, fundación Antonio Núñez Jiménez de la Naturaleza y el Hombre, la Habana. Disponible en: http://biblioteca.clacso.edu.ar/clacso/se/20191016023138/Los_procesos_de_organizac ion_agraria_en_Cuba.pdf

21. Van Dijk, J. (2005). The deepening divide: inequality in the information society. Thousand Oaks, California: Sage Pub. Disponible en: https://booksnow.com/book? isbn=9781412904025\&lang=en\&source=google. 